\title{
SISTEM PENERJEMAHAN KITAB PELAJARAN AKHLAK KE DALAM BAHASA INDONESIA MENGGUNAKAN METODE EUCLIDIAN DISTANCE
}

\author{
Wahyu Fuadi ${ }^{1}$, Maryana ${ }^{2}$, Ulfi Zahara ${ }^{3}$ \\ Jurusan Teknik Informatika, Fakultas Teknik, Universitas Malikussaleh \\ ulfizahara1@gmail.com ${ }^{3}$
}

\begin{abstract}
Abstrak
Abstrak - Kitab Pelajaran Akhlak adalah kitab yang berisikan tentang adab (etika) terhadap orang tua maupun seorang guru, adab dalam menuntut ilmu, dan penyakit hati yang ada pada diri manusia lainnya. Kitab Pelajaran Akhlak ditulis menggunakan bahasa Arab Melayu (jawi). Dikarenakan tidak semua orang mampu membaca dan memhami isi dari kitab pelajaran Akhlak, maka dari itu penulis merancang suatu sistem penerjemahan kitab Pelajaran Akhlak. Sistem ini bisa membantu pengguna dalam menerjemahkan isi dari kitab Pelajaran Akhlak dengan mudah. Dalam penelitian ini penulis menggunakan metode Euclidian Distance. Metode tersebut digunakan untuk menghitung jarak kemiripan pola kata dan terjemahan pada citra kitab Pelajaran Akhlak. Hasil pengujian menunjukkan bahwa keakuratan sistem ini sebesar86,72\%. Persentase detection rate(akurasi) tersebut menunjukkan Metode Euclidian Distance dapat digunakan sebagai salah satu pendekatan untuk pengenalan pola kata dan terjemahan pada citra kitab ini. Selain itu, Sistem Penerjemah Kitab Pelajaran Akhlak juga memiliki false positive rate 13,28\%, dikarenakan faktor kemiripan maupun perbedaan setiap citra pola kata uji dengan latih dari kitab pelajaran Akhlak.Namun, proses keakurasiannya dapat ditingkatkan dengan memberikan pelatihan lebih lanjut dengan tambahan data training yang lebih banyak dan lebih bervariasi.
\end{abstract}

Kata Kunci : Sistem Penerjemah, Kitab Pelajaran Akhlak, Euclidian Distance. 


\section{Pendahuluan}

Setiap muslim memiliki pedoman hidup untuk mengetahui tentang hukum yang berlaku dalam agama islam. Kita sebagai umat islam harusnya mengetahui tentang kewajiban kita sebagai umat islam dalam kehidupan sehari-hari. Sebagian besar muslim belum memahami tentang peraturan-peraturan yang berlaku dalam agama islam. Kitab merupakan pedoman bagi umat islam setelah Al-Qur'an dan Hadist.

Kitab Pelajaran Akhlak adalah kitab yang berisi tentang nasihat maupun tata cara berperilaku di dalam kehidupan seharihari. Misalnya adab (etika) terhadap orang tua maupun seorang guru, adab dalam menuntut ilmu, dan juga tentang bagaimana memuliakan ilmu dan lain-lain. Namun disini penulis akan membahas lebih detail tentang bab (pasal) berbakti kepada ibu bapak.

Kitab pelajaran akhlak dibuat dalam bahasa Arab Jawi sehingga tidak semua orang bisa membacanya dengan benar. Sebaiknya sebelum mempelajari bacaan dari isi kitab terlebih dahulu pengguna (user) mempelajari huruf Arab yang terdapat dalam kitab suci Al-Qur'an, hal ini dikarenakan bentuk penulisannya yang sangat mirip dengan penulisan huruf Arab yang terdapat dalam kitab suci Al-Qur'an. Oleh karena itu, diperlukan suatu sistem yang bisa menterjemahkan kitab Arab Jawi pada kitab pelajaran akhlak ke dalam Bahasa Indonesia. Supaya pengguna (user) lebih mudah dalam membaca dan memahami isi dari kitab pelajaran akhlak.

Dalam penelitian ini, penulis mengembangkan sistem yang menggunakan metode Euclidian Distance. MetodeEuclidian Distance merupakan metrika yang paling sering digunakan untuk menghitung kesamaan dua vektor. Metode tersebut merupakan metode yang sangat cocok untuk menterjemahkan citra bahasa, selain itu metode tersebut merupakan metode yang lebih sederhana yang dapat mempermudah penulis dalam membuat kombinasi citra bahasa jawi pada kitab pelajaran akhlak sebagai input data untuk mendapatkan pola terjemahan kedalam Bahasa Indonesia. Citra yang diuji nantinya akan terdeteksi terjemahan ke dalam bahasa Indonesia dari bagian kitab yang telah diinputkan 
di dalamnya sehingga pengguna (user) dapat dengan mudah membaca kata demi kata yang terdapat di dalam kitab pelajaran akhlak.

\section{Tinjauan Pustaka}

A. Pengertian Penerjemahan

Penerjemahan berasal dari kata dasar 'terjemah' yang berarti mengalihbahasakan.Sementara itu dalam bahasa Inggris, istilah penerjemah disebut translation. Nida dan Taber(1969) di dalam Bramono(2012) menjelaskan bahwa penerjemahan adalah usaha menciptakan kembali pesan dalam bahasa sumber(BSu) kedalam bahasa sasaran(BSa) dengan padanan alami yang sedekat mungkin, pertama-tama dalam hal makna dan kemudian gaya bahasanya. Dalam hal yang sama, Brislin(1976) didalam Bramono(2012) mengatakan bahwa penerjemahan adalah istilah umum yang mengacu pada pengalihan pikiran atau gagasan dari suatu bahasa sumber ke dalam bahasa sasaran. Pendapat ahli diatas cenderung sama dengan menggunakan bahasa yang berbeda. Tetapi pada intinya adalah, penerjemahan tidak hanya mengganti bahasa dalam bahasa sumber ke dalam bahasa target ,tetapi juga memindahkan makna. Karena, pembaca bahasa sasaran ingin mengetahui maksud dan keinginan penulis yang tertulis dalam bahasa sumber(Bramono, 2012).

B. Pengertian Kitab Pelajaran Akhlak

Kitab Pelajaran Akhlak adalah kitab Arab Melayu (Arab Jawi) yang berisi tentang adab (etika) terhadap orang tua maupun seorang guru, adab dalam menuntut ilmu, penyakit hati yang ada pada diri manusia serta bagaimana cara agar terhindar dari penyakit hati tersebut dan juga berisikan tentang bagaimana memuliakan ilmu. Jawi adalah salah satu bentuk tulisan kuno yang digunakan oleh rakyat melayu, khususnya yang ditulis dengan menggunakan tulisan huruf arab melayu. Rakyat melayu menggunakan bahasa ini untuk bekerja sama, berinteraksi, dan mengidentifikasikan diri. Huruf Jawi adalah sebuah sistem tulis yang sudah berabad-abad lamanya di Nusantara. Kemunculannya berkaitan secara langsung dengan kedatangan agama Islam ke 
Nusantara. Tulisan Jawi berasal dari tulisan Arab dan merupakan huruf Arab yang dimasukkan dalam sistem penulisan bahasa Melayu. Bukti terawal tulisan Jawi ini berada di Malaysia adalah dengan adanya Prasasti Terengganu yang bertarikh 70 Hijriah atau 13 Masehi. Tarikah ini agak problematis sebab bilangan tahun ini ditulis, tidak dengan angka. Di sini hanya bisa terbaca tujuh ratus dua: $702 \mathrm{H}$. (Nuril $\mathrm{A}, 2006$ ).

\begin{tabular}{|c|c|c|c|c|c|c|}
\hline$\dot{r}$ & $r$ & 8 & $\ddot{\leftrightarrows}$ & 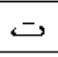 & $\hookrightarrow$ & 1 \\
\hline ش & ent & 3 & $j$ & 3 & $\Xi$ & 0 \\
\hline 3 & $\dot{E}$ & $\varepsilon$ & 占 & L & $\dot{\omega}$ & $\infty$ \\
\hline \multirow[t]{2}{*}{$\infty$} & \multirow[t]{2}{*}{9} & $\dot{4}$ & $\rho$ & th & S & $\sqrt{3}$ \\
\hline & & $\omega$ & $\xi$. & e & 5 & $\omega$ \\
\hline
\end{tabular}

Gambar 2.1 Huruf Jawi Dasar

(sumber: Nuril A, 2006)

\section{a. Citra}

Citra atau gambar dalam bahasa latin imago adalah suatu representasi, kemiripan atau imitasi dari suatu objek atau benda. Citra dapat dikelompokkan menjadi citra tampak dan citra tidak tampak. Contoh citra tampak dalam kehidupan sehari-hari berupa foto, gambar dan lukisan, sedangkan citra tidak tampak misalnya data gambar dalam file (citra digital) dan citra yang direpresentasikan menjadi fungsi matematis. Di antara jenis citra tersebut, hanya citra digital yang dapat diolah menggunakan komputer. Jenis citra lain, jika hendak diolah dengan komputer, harus diubah menjadi citra digital, misalnya foto discan dengan scanner, persebaran panas tubuh foto ditangkap dengan kamera infra merah dan diubah menjadi informasi numeris, informasi densitas dan komposisi bagian dalam tubuh manusia ditangkap dengan bantuan pesawat sinar-x dan sistem deteksi radiasi menjadi informasi digital. Kegiatan untuk mengubah informasi citra fisik non-digital menjadi digital disebut sebagai pencitraan (imaging)(Wikaria Gazali, 2012). 
Citra merupakan istilah lain untuk gambar sebagai salah satu komponen multimedia yang memegang peranan yang sangat penting sebagai bentuk informasi visual. Citra mempunyai karakteristik yang tidak dimiliki oleh data teks, yaitu citra kaya dengan informasi. Secara harfiah, citra (image) adalah gambar pada bidang dwimatra (dua dimensi). Ditinjau dari sudut pandang matematis, citra merupakan fungsi menerus (continue) dari intensitas cahaya pada bidang dwimatra. Sumber cahaya menerangi objek, objek memantulkan kembali sebagai dari berkas cahaya tersebut. Pantulan cahaya ini ditangkap oleh alat-alat optik, misalnya mata pada manusia, kamera, pemindai (scanner) dan sebagainya. Sehingga bayangan objek yang disebut citra tersebut terekam (Yuda Permadi, 2015).

\section{Citra resize}

Citra resize merupakan hasil perubahan ukuran citra asli ke ukuran yang telah disesuaikan sesuai kebutuhan sistem dan akan disimpan dalam bentuk .bmp. Hal ini dilakukan agar proses kerja sistem lebih cepat dalam menghitung koordinat citra (Cut Fadillah, 2015).

\section{Citra berskala keabuan (Grayscale)}

Citra berskala keabuan adalah citra yang menggunakan warna abu-abu yang merupakan kombinasi antara hitam dan putih. Setiap warna didalam citra berskala keabuan dinyatakan dengan sebuah nilai bulat antara 0 dan 255 (untuk yang arah keabuannya sama dengan 256) dan nilai tersebut disebut sebagai intensitas. Di dalam pengolahan citra, citra berwarna seringkali dikonversi terlebih dulu ke citra berskala keabuan. Kemudian, melalui citra berskala keabuan inilah dilakukan pemprosesan, misalkan untuk memperoleh tekstur objek (Cut Fadillah, 2015).

Untuk mengubah citra berwarna menjadi nilai matrik masing - masing R, G dan B menjadi citra gray-scale dengan nilai S, maka konversi dapat dilakukan dengan mengambil nilai rata-rata dari R, G dan B sehingga dapat dituliskan menjadi:

$s=\frac{r+y+b}{3}$ 
Keterangan : $\mathrm{S}=$ Warna Grayscale (Pixel)

$$
\begin{aligned}
& \mathrm{R}=\text { Warna Merah (Pixel) } \\
& \mathrm{G}=\text { Warna Hijau (Pixel) } \\
& \mathrm{B}=\text { Warna Biru (Pixel) }
\end{aligned}
$$

\section{Metode penelitian}

Tahap pemrosesan metode Euclidian Distance pada sistem penerjemah Kitab Pelajaran Akhlakadalahuntuk mendapatkan gambaran mengenai keakuratan distance (jarak) dua buah vektor dalam aplikasi sistem ini.Berikut adalah contoh penjabaran rumus dari metode Euclidian distance untuk mengetahui jarak dua buah vektor dalam aplikasi ini.

Diketahui :

$$
\begin{aligned}
& d_{i,}=[1143,245,781,897,605] \\
& d_{j}=[1142,243,778,894,604]
\end{aligned}
$$

Penyelesaiannya :

$$
\begin{aligned}
& d_{i}=\sqrt{\sum_{\mathrm{k}=1}^{\mathrm{N}}\left(d_{i i}-d_{j}\right)^{2}} \\
& d_{l} \\
& =\sqrt{(1143-1142)^{2}+(245-243)^{2}+(781-778)^{2}+(897-894)^{2}+(605-604} \\
& =\sqrt{(1)^{2}+(2)^{2}+(3)^{2}+(3)^{2}+(1)^{2}}=\sqrt{1+4+9+9+1}=\sqrt{24}=4,89
\end{aligned}
$$

Penjabaran rumus diatas adalah proses mencari nilai jarak antara pola uji dan latih. Selanjutnya nilai tersebut menjadi acuan kemiripan citra dengan pola yang sudah ditanam. Nilai jarak Euclidian = 4,89 menandakan jarak pola latih dan uji bernilai 4,89. Dalam artian lain, jika nilai jarak citra mendekati nilai jarak uji tersebutmaka pola dan terjemahan kitab pelajaran Akhlak akan terdeteksi.

Penjabaran rumus yang telah digunakan di atas merupakan suatu proses perhitungan manual untuk mencari nilai jarak antara pola yang telah dilatih dan diuji. Berdasarkan nilai yang sudah didapatkan melalui tahapan-tahapan tersebut akan menjadi pedoman image similarity (kemiripan citra) dengan pola katadari kitab Pelajaran Akhlakyang sudah ditanam di dalam sistem. 


\section{Hasil dan Pembahasan}

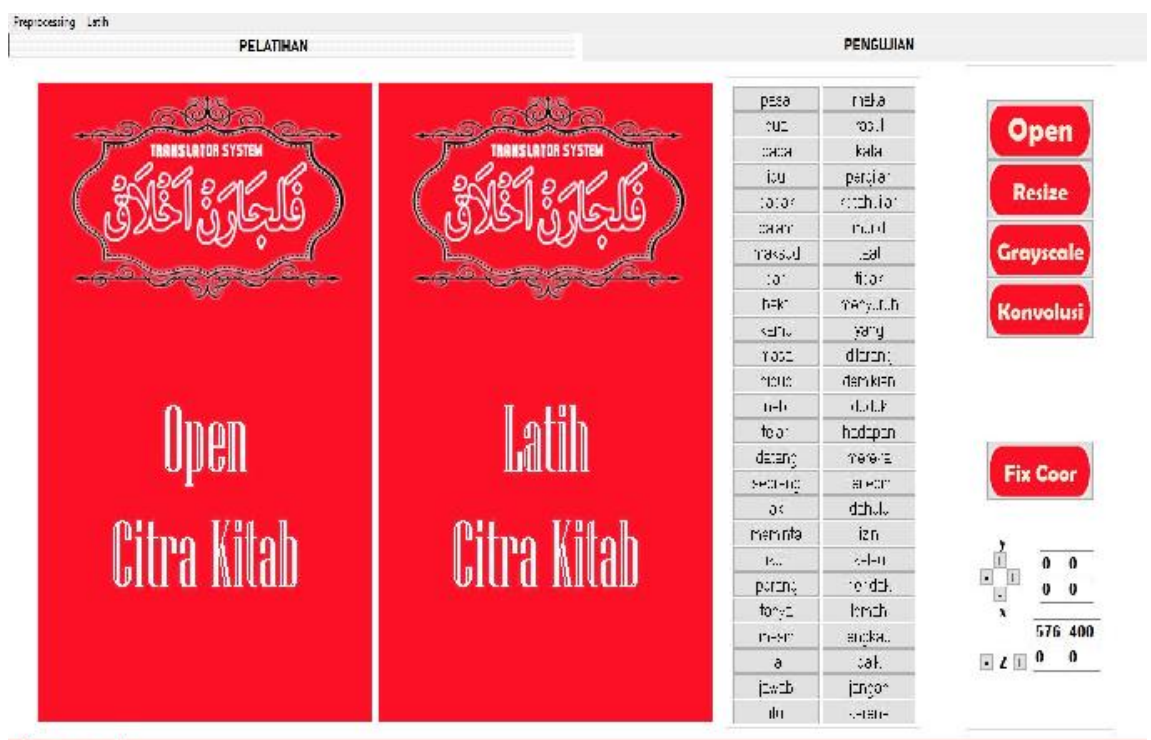

Pada bidang sebelah kanan halaman form juga terdapat2 page control yang digunakan masing-masing untuk memilih halaman pelatihan dan pengujian pola penerjemah ini.Untuk berpindah atau berganti halaman dari pelatihan ke pengujian pola atau sebaliknya pengguna (user) bisa menekan tombol button pengujian dan pelatihan yang ada di sebelah kanan layar. Pada halaman pengujian pola kata juga terdapat Preprocessing yang berfungsi untuk membuka citra kitab Pelajaran Akhlak yang akan dideteksi atau dapat diakses dengan menekan tombol "Open". Setelah citra kitab dibuka, user langsung bisa menekan tombol "Terjemah" yang ada disebelah kanan citra inputan citra kitab Pelajaran Akhlak yang ingin diterjemahkan. Disamping itu halaman ini juga dilengkapi dengan pilihan nilai sensitifitas untuk menemukan pola yang ada dan juga keterangan warna yang berbeda-beda sehingga bisa membedakan mana saja pola terjemah kata dari kitab tersebut. 


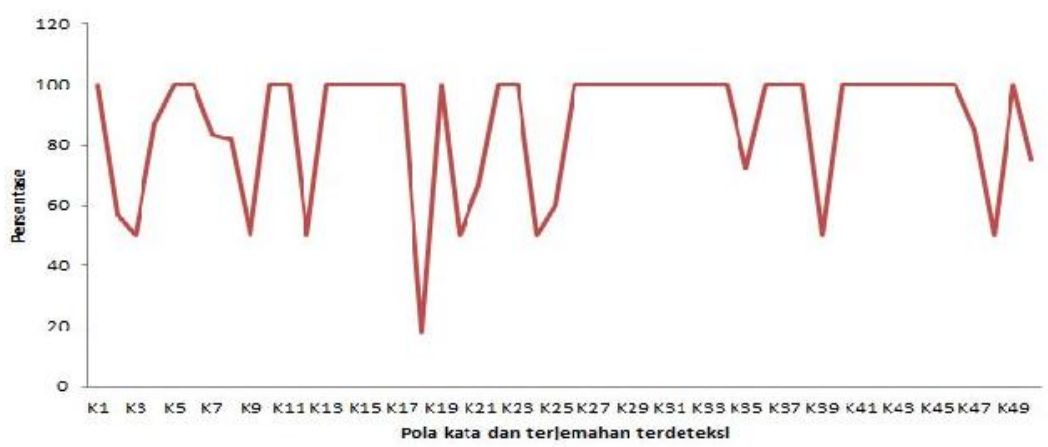

Gambar 4.2 Grafik Unjuk Kerja Sistem Penerjemah Kitab Pelajaran Akhlak Menggunakan MetodeEuclidian Distance

Dari hasil pengujian untuk 50 sampel pola dan terjemahan kitab Pelajaran Akhlak menunjukkan bahwa tingkat kebenaran pengenalan pola kata dan terjemahannya tergantung pada citra yang objeknya tidak terlalu banyak mengandung noise. Gambar grafik 4.15 mendeskripsikan 50 vektor pola kata pada citra kitab Pelajaran Akhlak yang sudah dilatihsebagaipengujian dan pengukuran unjuk kerja.Hasil observasi dan evaluasi hasil research (penelitian) terhadap4halaman kitab Pelajaran Akhlak menghasilkan rata-rata persentase keberhasilan proses pendeteksian pola kata dan terjemahan kitab Pelajaran Akhlak mencapai $86,72 \%$, sedangkan persentase rata-rata kesalahan pengenalan pola dan terjemahannya sebesar $13,28 \%$.

\section{Kesimpulan Dan Saran}

Kesimpulan pada penelitian ini didapatkan dari beberapa proses pelatihan dan pengujian sampel citra kitab Pelajaran Akhlak yang diterjemahkan dengan menggunakan Metode Euclidian Distance, maka hasil yang diperoleh dari beberapa proses penelitian dapat dirincikan sebagai berikut:

1. Penelitian ini menunjukkan bahwa Sistem Penerjemah Kitab Pelajaran Akhlak menggunakan Metode Euclidian Distancememiliki rata-rata detection rate $86,72 \%$. 
2. Jumlah banyaknya sampel yang dilatih atau diuji mempengaruhi keakuratan sistem penerjemah kitab ini.

3. Sampel citra kata arab-jawi yang dijadikan pelatihan sangat berdampak terhadap tingginya persentase keberhasilan pendeteksian masing-masing pola.

4. Faktor faktor kemiripan maupun perbedaan setiap citra polakata arab-jawilatih dari kitab Pelajaran Akhlak menjadi salah satu kelemahan pada sistem ini sehingga false positive rate akan muncul. 


\section{Daftar Pustaka}

Bramono, Nurdin. 2012. Kompetensi Penerjemahan (Penerjemah Sebagai Bentuk

Wirausaha).(http://www.journal.unipdu.ac.id/index.php/ seminas/article/download/151/98, diakses tanggal 15 Oktober 2018 )

Dahria, Muhammad. at al 2013.Pengenalan pola wajah menggunakan webcam untuk absensi dengan metode wavelet. Vol 2 No 2. (http://lppm.trigunadharma.ac.id, diunduh pada tanggal 27 Agustus 2018).

Fadillah, Cut. 2015. Sistem Pendeteksi Pola Tajwid Al-Qur'an Hukum Idgham Bighunnah Dan Bila-Ghunnah Menggunakan Metode Nei And Li. Tugas akhir. Prodi Teknik Informatika.Universitas Malikussaleh. Bukit Indah.

Fitriawan, Helmy. at al. 2013.Identifikasi Plat Nomor Kendaraan Secara Off-Line Berbasis Pengolahan Citra dan Jaringan Syaraf Tiruan. (http://download.portalgaruda.org, diakses pada tanggal 19 Agustus 2018).

Gazali, Wikaria. at al 2012. Penerapan Metode Konvolusi Dalam Pengolahan Citra Digital. Jurnal Matematika dan Statistik Vol 12 No 2 , Juli, 2012. (http:/ / researchdashboard.binus.ac.id/uploads/paper/doc ument/publication/Journal/MatsTat/Vol. \%2012\%20No. $\% 2$ 02\%20Juli\%202012/01_Wikaria\%20Gazali.pdf, diakses tanggal 30 Agustus 2018).

I Wayan Suartika E. P. at al. 2016. Klasifikasi Citra Menggunakan Convolutional Neural Network (Cnn) pada Caltech 101, Jurnal Teknik Its Vol. 5, No. 1, (2016) ISSN: 2337-3539.

Kadir, Abdul. 2013. Dasar Pengolahan Citra dengan Delphi. Yogyakarta. Penerbit Andi. 
Sistem Penerjemahan Kitab Pelajaran Akhlak ke dalam Bahasa Indonesia menggunakan Metode Euclidian Distance

102

Munandar, Imam. 2013. Implementasi Algoritma Deteksi Tepi Untuk Menentukan Kualitas Surface Pada Mutiara Laut Dengan Menggunakan Metode Sobel(Study Kasus PT. Autore Pearl Farm Show Room). (https://caridokumen.com/download/deteksi-tepimenggunakan-metode-sobel_5a44ac67b7d7bc7b7a7a9e0d_pdf, diakses tanggal 6 September 2018).

Nuril A., at al. 2006. Perangkat Lunak Bantu Mengenal Huruf Arab Melayu Ke Bentuk Huruf Latin Bahasa Indonesia, vol. Vol.8 No.3, diakses tanggal 6 September 2018.

Permadi, Yuda and Murinto. 2015. Aplikasi Pengolahan Citra Untuk Identifikasi Kematangan Mentimun Berdasarkan Tekstur Kulit Buah Menggunakan Metode Ekstraksi Ciri Statistik. Jurnal Informatika Vol 9 No 1, Januari, 2015.(http://journal.uad.ac.id/index.php/JIFO/article/dow nload/2044/1308, diakses tanggal 6September 2018).

Pressman, 2013. Unified Modeling Languange. Yogyakarta. Penerbit Graha Ilmu.

Rachmat, Sendhy Wurdianarto, dkk. 2014. Perbandingan Euclidean Distance Dengan Canberra Distance Pada Face Recognition.Jurna Techno.COM, Vol. 13, No. 1, Februari 2014: 3137(https:// publikasi.dinus.ac.id/index.php/technoc/article /view/539, diakses tanggal 19 September 2018)

Ridho Barakbah, Ali. at al. 2013. Logika dan Algoritma. Politeknik Elektronika Negeri Surabaya. Surabaya

Rosa, Salahuddin, M. 2014. Rekayasa Perangkat Lunak Terstruktur dan Berorientasi Objek. Bandung. Informatika.

Sutabri, Tata. 2012. Analisis Sistem Informasi. Yogyakarta : Andi. 
Wakhidah, Nur. 2012. Deteksi Plat Nomor Kendaraan Bermotor Berdasarkan Area pada Image Segmentation. Jurnal Transinformatika, Vol 9 No 2 Januari, 2012. (http://journals.usm.ac.id/index.php/transformatika/58/5 8, diakses tanggal 6 September 2018).

Wardoyo, Siswo. 2014. Sistem Pesensi Berbasis ALgoritma Eigenface Dengan Metode Principal Component Analysis. Jurnal SETRUM Vol 3, No 1, Juni 2014. (https://jurnal.untirta.ac.id/index.php/jis/article/viewFile /498/386, di akses tanggal 22 September 2018) 